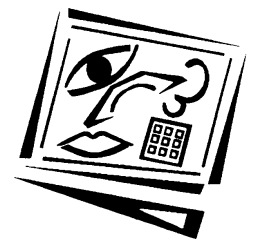

\title{
Towards understanding the potential of e-portfolios for independent learning: A qualitative study
}

\author{
Juliana Chau \\ The Hong Kong Polytechnic University \\ Gary Cheng \\ The Hong Kong Institute of Education
}

\begin{abstract}
This paper discusses the findings of a research study concerning the use of e-portfolios to develop independent learning, from the perspectives of teachers and students in a Hong Kong university. While most of the findings confirm the value of e-portfolio practice reported in other contexts, they throw into relief a complicated interplay and conflict of factors that may thwart the good intentions of e-portfolio design and implementation. Insights derived from this research will illuminate the issues about eportfolio-mediated independent learning across a range of settings and learners.
\end{abstract}

\section{Introduction}

The pace of utilising information technologies to support learning in higher education has accelerated over the past two decades, encouraged in part by research findings that technologies could provide improved support and added value for student learning. This development generally pursues two directions: through 'e-initiatives' adopted by educational institutions worldwide to formalise the process of assembling student work as a means to showcase student achievements over time (Foti \& Ring, 2008; Meeus, Van Petegem \& Engels, 2009), and secondly, through the use of participatory tools, including podcasts, wikis, blogs and other social networking software, to offer more personalised learning opportunities for students (Moskaliuk, Kimmerle \& Cress, 2009; Richardson, 2009; Yang, 2009).

As advocated by cognitive constructivism, students construct new knowledge based upon their prior experience and personal interpretation of the world rather than passive reception of information (Piaget, 1971). Hence, learning should build on students' existing knowledge about a given topic and improve this understanding (Kolb, 1984). However, the perception of traditional institutions being places that disengage learners persists: honest self-assessment is rarely encouraged, and 'learning and evaluation are not meaningful acts of improvement but detached and punitive symbols of failure' (Abrami et al., 2008, online). One possible way to engender a paradigm shift to a more learner-centred approach is through the introduction of electronic portfolios (e-portfolios) to support learning (Herrington et al., 2009; Little, 2009; Stoicovy \& Sanchez, 2007).

Recent literature on e-portfolio practice validates e-portfolios as a platform which allows learners to collect, organise and present digital evidence in a variety of media types over time, for different purposes and audiences (Hartnell-Young et al., 2007; 
Joyes, Gray \& Hartnell-Young, 2010). In general, three types of purposes can be identified (Milman \& Kilbane, 2005). The first purpose is for students to develop, demonstrate and reflect on their own learning (Stefani, Manson \& Pegler, 2007; JISC, 2008). The second is to provide teachers with a form of assessment other than standardised testing, by capturing more fully the multi-faceted, complex nature of student learning (Cummins \& Davesne, 2009), while the third is for graduates to showcase their competence to potential employers in job applications (Willis \& Wilkie, 2009).

\section{Electronic portfolio and independent learning}

Since e-portfolio design and implementation often subscribe to socio-constructivist pedagogies (Abrami \& Barrett, 2005), e-portfolio users are conceptualised as active agents involved in constructing knowledge, refining their understanding, and learning socially through sharing with peers and teachers. E-portfolio practice, in this sense, intersects with notions of independent learning in two important ways: personalised learning and learner responsibility.

On personalised learning, Abrami and Barrett's (2005) observation is pertinent:

[e-portfolios] encourage learners to explore topics from a personal perspective capitalizing on and potentially increasing intrinsic interest. Intrinsic interest and the involvement in authentic learning tasks may also lead to [an] increased... sense of personal commitment and ownership. (online)

Little (1995) articulates his view on learner responsibility thus:

[An autonomous learner] accepts responsibility for his or her learning. This acceptance of responsibility has both socio-affective and cognitive implications... [involving] a positive attitude to learning and the development of a capacity to reflect on the content and process of learning with a view to bringing them... under conscious control. (p.175)

A review of the literature on independent learning commonly produces two related terms - learner autonomy and self-regulated learning - that overlap and vary to a certain extent. Deci (1996) distinguishes autonomy from independence, and argues that autonomy 'means to act freely, with a sense of volition and choice', whereas 'independence means to do for yourself, to not rely on others for personal nourishment and support' (p.89). According to Zimmerman (2000), self regulation refers to 'selfgenerated thoughts, feelings, and actions that are planned and cyclically adapted to the attainment of personal goals' (p.14). For Andrade and Bunker (2009), autonomy encompasses metacognition, strategic competence, reflection, freedom of choice as well as decision making about what and how to learn, self direction and accepting responsibility. The concept of self-regulated learning, on the other hand, tends to highlight a need to guide learners towards 'being effective without reliance on teacher structure' (p.49), with learner choice being a secondary goal. Recent interest in linking independent learning to other learner-centred constructs like self motivation, agency and identity has increasingly obfuscated the boundaries of independent learning as a field (Benson, 2006).

The use of the term 'independent learning' in this paper is referenced mainly from the works of Andrade and Bunker (2009), Benson (2006), Deci (1996) and Zimmerman (2000). It is understood as the way students make use of an iterative process to regulate 
their own learning. The process typically involves the following three phases (Pintrich, 2000; Winne, 2001, Zimmerman, 2000):

- Planning: setting goals and activating prior knowledge

- Monitoring: reviewing one's progress towards the goals

- Reflecting: modifying goals and/or adopting repair strategies

By definition, apart from being viewed as a collection of digital artifacts for showcasing a student's understanding and achievement, e-portfolio use is a means for formative development through a student-oriented and performance-based process of 'planning, synthesising, sharing, discussing, reflecting, giving, receiving and responding to feedback' (JISC, 2008, p.6), which is consistent with the above phases that characterise independent learning. Since e-portfolio compilation is not content specific, it allows flexibility to furnish students with both disciplinary knowledge and employability skills such as self management and teamwork for lifelong and lifewide learning (Cambridge, 2008). For these reasons, e-portfolios hold promise of supporting innovative educational initiatives in tertiary institutions to stimulate and challenge students to become self initiated and self regulated learners visible to major stakeholders - employers, professional bodies, assessors, and the public - in times of increased accountability and quality reviews.

To date, most research in promoting independent learning through e-portfolio practice has been undertaken in Anglo-American and European contexts (Abrami et al., 2008, Kicken et. al, 2009; Meeus, van Petegem \& Meijer, 2008), with limited research on similar areas being conducted in Asia. Therefore, this paper aims to fill this gap by exploring the potential and identifying the challenges of using e-portfolios to support independent learning in Chinese higher education. The ensuing sections of this paper report and analyse the findings from an e-portfolio competition at The Hong Kong Polytechnic University (PolyU) with a predominantly Chinese student population. Insights derived from this initiative will illuminate issues emanating from the development of e-portfolios for independent learning in other contexts.

\section{Context}

The English Language Centre of The Hong Kong Polytechnic University has employed a blended mode of delivery for most of its English (as a second language) courses and implemented a range of e-learning initiatives to promote independent language learning. An e-portfolio was developed and integrated into four selected English language courses with an average of 18 students in each course between 2007 and 2008. The main aim was to enable students to utilise the e-portfolio as an extra language learning tool to chronicle and demonstrate their learning progression and accomplishments in English, as well as competence and confidence with technology, to peers, teachers and prospective employers. A complementary aim was added in 2009 to widen student participation across a range of academic disciplines to foster independent language learning through e-portfolios. To this end, an e-portfolio competition was launched between February and April 2009 (see Appendix 1 for rubrics and details). Except for the specified number of documents and timeframe, students enjoyed freedom of choice concerning their learning goal, content or type of artifact to be showcased, and the mode or frequency of communication with their eportfolio teacher - online or face to face, the latter to be mutually arranged. There was no requirement for peer feedback. Competition-related information was disseminated through emails, posters, videos, and subject teachers. 


\section{Rationale of the study}

This paper aims to examine the potential and identify the challenges of supporting eportfolio-mediated independent learning for Chinese university students, given the dearth of systematic research in this field. Our attention is focused on students' and teachers' perception of independent learning rather than language improvement, as fostered by e-portfolios. Specifically, the study sought to address the following two questions using qualitative data analysis:

- What are the views of university students and teachers on e-portfolios for developing independent learning?

- What challenges exist in developing independent learning through e-portfolios at university?

\section{Methodology}

\section{Participants}

The participants in this study were 63 Chinese undergraduate students at The PolyU who voluntarily signed up for an e-portfolio competition held between February and April 2009. They came from 21 academic disciplines including Accounting, Applied Science, Engineering, Hotel and Tourism, Language, Logistics, Management, Nursing as well as Textile and Clothing. Their ages ranged from 19 to 22 years. Furthermore, our study invited 13 English language teachers (four non-native and nine native speakers) at The PolyU to serve as cheerleaders (providing encouragement), language experts (advising students on language matters), and facilitators (offering guidance on independent language learning) throughout the competition. Their teaching experience in this field ranged from a year to over a decade. Since all participants had little or no experience of creating a web-based e-portfolio, they attended a workshop to familiarise themselves with the concept and process of e-portfolio use prior to the competition.

\section{Research design}

Understanding the e-portfolio experiences of participants and seeking to identify ways in which such experiences are understood or perceived by participants constitutes the core of this research. A qualitative research paradigm that puts a premium on understanding the intricacy of human realities rather than on statistical analysis was adopted by drawing on the techniques of grounded theory (Charmaz, 2006; Silverman, 2001; Strauss \& Corbin, 1990) as a means of data analysis, and interviews (Gillham, 2000; Mishler, 1986) as a way of generating data. Such techniques were chosen mainly for their flexibility that would facilitate emerging themes from the coded data through constant comparative analysis.

\section{Data collection and analysis}

Data was obtained mainly from post-event semi-structured interviews with individual participants (Appendix 2), complemented by documentary evidence (artifacts) in students' e-portfolios; and students' reflective entries (Appendix 3). The interviews were audio-recorded and subsequently transcribed verbatim. The first level of data analysis involved data reduction through summarising, coding, memoing and 
identifying major clusters labeled as 'categories'. At the next stage common categories that recurred in the transcripts were identified. Categories that appeared to cluster together were linked together to form a theme. However, when the linkages between the categories and the emerging themes appeared obscure, cross-checking with interview transcripts, students' e-portfolio evidence and reflection was conducted to ensure data consistency.

Five major themes emerged as significant for understanding e-portfolio-mediated independent learning: 1) choice and ownership; 2) feedback; 3) technological competence; 4) self-improvement and strategies; and 5) dual perception. In the ensuing sections, the five major themes and their relationship with the process of independent learning are discussed.

\section{Results}

For e-portfolios to be widely adopted as an independent learning tool, the buy-in from teachers and students plays a crucial role. An analysis of interview transcripts, students' e-portfolio evidence and reflective commentary which produced five emergent themes contributes to an expanded understanding of the issue.

\section{Theme 1: Choice and ownership}

A recurring theme was the notion of choice and ownership. Although the e-portfolio was standardised in its presentation, comprising templates and guidelines for evidence selection, and self-reflection on how evidence connected to the identified goals, students could identify their own goals, and include artifacts of their choice in an attempt to balance their need for specific help and flexibility to allow for creativity and ownership. The fact that students no longer had to refer to any course syllabi or lecture notes, apart from the e-portfolio competition rubrics (Appendix 1), to complete a self-initiated task was seen as an advantage, as shown by the following student comments:

- One good thing about the e-portfolio is there is no restriction on the choice of materials I can present, like my videos, documents and MP3...I can be creative in the way I do things.

- The thing about independent learning is we just do it willingly...we can choose to upload text, video or audio on to the e-portfolio, or have a description for each showcase. It's very flexible.

- I feel close to the e-portfolio; it's not like an assignment. I think you should position an e-portfolio not as a school task or assignment, but treat it like something you want to own, and have a sense of belonging. Then you'll be more motivated and feel responsible for keeping it.

Provision of individual choice in the e-portfolio was supported by a teacher's comment:

- The major aspect in my view is it [the e-portfolio] gives students another way to learning language. Some people really like the electronic media. Personally, it's not the way I work. But many young people are quite comfortable with working online and I think that gave them an opportunity to do something at home or anywhere else and in a way that relates to their own language learning.

Another teacher added that individual choice and thought are crucial to establish a sense of ownership: 
- With this e-portfolio, I don't think there is any sense of ownership as it seems like they are asked to do it. Actually, I was one of the first batch of staff involved in the design a paper-based portfolio, like a learner diary. We thought about what we should put in and went through the whole process of developing the whole thing...that, I feel, is my sense of ownership.

\section{Theme 2: Feedback}

In general, peer feedback was hardly found because it was not mandatory in the competition. Students tended to assign less significance to peer comments, but consistently agreed on the usefulness of teacher feedback for language learning in both cognitive and affective terms. Teachers concurred, while highlighting a need for better understanding the correlation between student performance and the type and level of teacher feedback in an e-portfolio environment.

From students:

- It is very interesting because I know the teacher...I was satisfied with my files, and was very happy to communicate with him, using this platform.

- Teacher feedback makes you have a better feel of what you have learned or what you have submitted. Because if no one points out your mistakes, you will never know...[Teacher] feedback helps me to make small, regular progress over a period of time.

- I'm happy that the teacher helps to review my progress and there's someone to appreciate and share my work.

From teachers:

- For me, it almost like a two-way relationship...you see a video, you read some commentary, and I respond, but to encourage them to respond to me, I always end with a question, not just a yes or no question, but I will say something like...how did you find your holiday in New York? What are the things that you remember most? Something that encourages them to come back, but avoid the trap of reducing the e-portfolio to an email exchange.

- I'd love to see an example of somebody giving negative feedback...to point out a weakness and how to give students guidance.

- We need to define clearly the role of facilitator, what kind of feedback because we're not their subject teacher.

\section{Theme 3: Technological competence}

Competence with technology was another theme. Both student and teacher responses indicated that learning how to use the e-portfolio effectively for independent learning would hinge on one becoming computer literate and conversant with alternative interaction patterns supported by the e-portfolio system.

\section{Student perspectives:}

- It's challenging to create evidence in digital format as I do not have particularly good computer skills. I am comfortable with using word document or sound recordings, but when you talk about videos, you need to edit them, which is difficult and so I avoided uploading videos.

- With our assignment, I can put it on my desk to remind myself, but with the eportfolio, you don't actually see it. With the Internet, you may forget where the site might be...but with the e-portfolio, I can retrieve things easily. I understand it's a matter of adjustment. 
Teacher perspectives:

- I'm not particularly good at navigating my way through websites, but as soon as I'd done it a couple of times, I found it work very efficiently. I had to remember to check it regularly because I have many other duties during the semester.

- I can see students' videos and read what they have put in the e-portfolio. It generally worked well. I also saw one of the students face to face, and in our brief conversation, I got to know the kind of language level she had and the goals she set for her e-portfolio was realistic. So I was able to talk to somebody who was sensible.

\section{Theme 4: Self-improvement and strategies}

Unlike formal, structured learning which focuses almost exclusively on summative assessment results, student comments showed a shift of perception of learning to that of a process that accommodated a variety of learning preferences and facilitated strategies for self-improvement. Several teachers pointed out that e-portfolio use exerted metacognitive demands on students.

What students said:

- I need to keep writing, because I think the main benefit is I can learn English as a process. I can identify the area of English I need to learn more. As for my writing, my grammar is not very good and I like to write fast, I will make so many small mistakes. When I check the e-portfolio and see that it contains mostly reading materials or videos, I realise I should write more.

- Using the e-portfolio system can help me to think more, and also let me know which part I actually worked on and which part I had to do more.

What teachers thought:

- Setting goals requires skills, step by step, not too low, too ambitious, but sensible and realistic. This is not easy for students.

- I monitored the work they submitted, and it seems to me that there was some correspondence between the goals and the work. The goals are realistic, not crazy ones like to be a fluent English speaker in one semester.

- Everybody has a different way of learning a language; so sure, [e-portfolio use is] just another way of doing what we hope to do - that is to encourage interests in language learning and encourage students to develop a sense of awareness of their own language learning process.

\section{Theme 5: Dual perceptions}

The majority of students and teachers tended to perceive e-portfolio use as a tool conducive to learning as both a product and a process geared towards developmental performance. The dual perceptions, coincided with commonly cited definitions of eportfolios (JISC, 2008), were corroborated by the following remarks:

- It helps me to reflect and know what I have done over a period of time and what I need to do more to improve English. (student)

- I can practice English out of class using the e-portfolio and to keep a record of my English studies. (student)

- It's like a photo album; you look through and you like this piece of writing here and something else there. From a stack of what you've got - though now that is in e-form - you can carry around on a flash drive, and adapt, and change and develop and edit. It's good. (teacher) 
- It's like a diary which regularly records students' experience...for selfdevelopment, self-reflection and self-enrichment. (teacher)

\section{Discussion}

\section{Relationship between the five themes and independent learning}

An analysis of student and teacher responses, together with e-portfolio evidence and reflection, validates many of the benefits of e-portfolio practice reported in previous research, particularly regarding learners' increased sense of ownership (Little, 2009), helpful teacher feedback (Willis, Gravestock \& Jenkins, 2006), enriched learning experience at both individual and technological levels (Woodward \& Nanlohy, 2004), enhanced opportunity for self-improvement (Gülbahar \& Tinmaz, 2006), as well as heightened awareness of the learning process (Abrami \& Barrett, 2005).

In the previous section, the five emergent themes not only reaffirm the benefits of eportfolio practice, but also suggest that independent learning can be supported by such practice. The themes are closely linked to the three phases of independent learning: planning (Themes 1 and 3), monitoring (Themes 2 and 5), and reflecting (Themes 2 and 4).

Planning involves setting specific goals and performance outcomes for monitoring and evaluation (Zimmerman, 2000). Self-determined goals, aligned with one's own needs and interests, were reported to be more sustainable during goal pursuit and also more effective in goal accomplishment than the goals influenced by external encouragements or social pressure (Sheldon \& Elliot, 1998). In this connection, the characteristics of student choice and ownership (Theme 1) in e-portfolio use would enable students to exercise considerable control over their goal setting process. Another consideration for facilitating personal planning for growth is students' competence. As suggested by Pintrich and Schunk (2002), task outcomes should be designed within the range of students' ability for students to develop confidence and competence for successful task fulfillment. It is thus important to build and extend students' technological competence (Theme 3) required for effective e-portfolio practice.

Monitoring refers to the activities of observing the discrepancy between one's goal and current progress towards that goal, and of generating feedback that can guide further action (Pintrich, 2000). With the dual perceptions of e-portfolios in mind (Theme 5), students may appear to monitor their progress from a broader perspective in which the learning product and process are kept in focus. They may identify the need to improve the quality of outcomes, as well as to revise the strategies used in generating the outcomes. The self-monitoring process may yield insights for students, but feedback from external sources - from peers and teachers for example (Theme 2) - that confirms, adds to, or conflicts with students' understanding of their own progress (Butler \& Winne, 1995), is also found to be helpful in improving students' achievement.

Reflecting is perceived as students' judgments of, attributions for and reactions to their performance after monitoring (Pintrich, 2000). Awareness of the need for selfimprovement and the subsequent use of strategies for such improvement (Theme 4) are favorable outcomes of the reflecting activities; the value of both was confirmed by our findings on e-portfolio practice. To help students deploy effective strategies leading to 
successful improvement, feedback from peers and teachers (Theme 2) is believed to be an important source of input (Paris \& Paris, 2001).

While noting the potential of e-portfolios for promoting independent learning, three fundamental challenges at the levels of student, teacher and institution were observed during the research study. They include the 'clone' phenomenon of student performance, teacher identity, and institutional policy, which may influence successful implementation of e-portfolio-mediated independent learning. The details will be discussed in the next section.

\section{Challenges for e-portfolio-mediated independent learning}

The 'clone' phenomenon of student performance

A central challenge is that on the one hand, e-portfolios are primarily designed to be a personalised and individualised formative document to scaffold learners into planning, self-monitoring and self-reflection. The e-portfolios present evidence of learning progress, achievements and gaps in learning that may necessitate a need for review and change. Several students in this research commented positively on this aspect. On the other hand, e-portfolios are often viewed as a collection of summative documents intended as evidence for assessment of competence. This challenge is indicative of the wider tensions identified between the two main purposes - evaluative and developmental - that most e-portfolios serve. While the former is result-driven and characterised by standardisation, the latter is process focused, emphasising developmental performance, risk taking and creativity. Some students' e-portfolio artifacts in this research, albeit different in content, suggested that in order to meet competition requirements, a few students saw conformity to evaluation criteria as a more pressing imperative than individuality - qualities that make learning meaningful, thus producing 'clone' e-portfolios which resemble every other regardless of personal preferences or abilities. Implicit in this appears to be a question about deviation from the standard profile that might jeopardise their chance of success.

Language or education programs that require students to compile e-portfolios are trapped in a quandary when it comes to identifying purpose and audience. In one respect, suggesting that e-portfolios might accomplish multiple purposes contains an obvious risk of diluting the central focus of the e-portfolio task. In another, if we suggest e-portfolios are for a single purpose only - to meet a degree requirement or confer an award, we are likely to produce risk-averse students, especially among those who have neither the intent nor the ability to work independently. Scott (2005) cautions that any activity undertaken within institutional boundaries and is subjected to institutional criteria may compel students to 'create plausible narratives of curricular success' (p.27). In this way, the growth that can be gained from 'a more critical, more ambivalent, perhaps even an oppositional stance' (Scott, 2005) may be stunted.

\section{Teacher identity}

For much of the twentieth century, educators invariably concentrated on problems germane to teaching, leaving the learning dimension much neglected. This 'invisible learner' phenomenon held sway until the 1950s when some of the principles of psychology and the concept of 'learner centredness' and learner differences began to become widespread (Benson, 2005; Chamot, 2005). The swing of focus from that of teaching to learning means that teachers need to reconceptualise the changing teacherstudent relationship. Unfortunately, the wider aspects of the shifting teacher role in the 
twenty-first century have been under-investigated. Little (2009) identifies three challenges facing the development of independent learning, two of which are associated with the teacher: teacher doubt, teacher know-how, and the curriculum. Arkoudis and Love (2008) suggest a teacher identity as a site of struggle through their illustration of a teacher whose effort to recognise learner differential conflicts with her positioning of the students as less able, thereby inadvertently further alienating the students from the classroom community.

This feeling of unease is captured in some teachers' remarks in this research, as exemplified by this 'comet' metaphor to describe his or her e-portfolio experience:

- It's like watching comets - you never know when a new entry will arrive, and if the student will return.

A few teachers also drew attention to the need for negative feedback and a clear definition of teacher responsibility in independent learning, arguing that this could influence student expectations and workload. Such remarks can be interpreted as a sense of uncertainty about the changing educational landscape, in particular when the move from a directed, positivist paradigm (explanation, knowledge transmission, product as good or bad) to a constructivist one (inquiry, knowledge creation, process as unfolding) is often construed not as a continuum but as a dichotomy. With increasing application of technology, educators (Barnett, 1993; Little, 2009) warn against conceptualising independent learning as a polarity between a controlling teacher and a student learning alone, assisted by technology that 'seeks to achieve the independence of the learner not by developing his self-direction, learning skills and responsibility but by imitating as closely as possible traditional teacher roles which tend to control learners' (Barnett, 1993, p.296). The predicament is, where unpredictability and tentativeness which tend to mark the intricate nature of learning is widely debated and acknowledged, the challenges that teachers encounter and the ways they forge their identity have not attracted commensurate attention or recognition.

\section{Institutional policy}

Although e-portfolios have great potential as instruments for facilitating systematic planning of learning, as evidenced in this research, their implementation remains in its infancy in many places. The new learning environments require teachers and learners to change their routines: from lecturing to listening, from coaching to participating. This process of change demands adequate support in both technical and pedagogical terms, without which resistance to or frustration with change can be easily projected onto the e-portfolio as one of the most visible symbols of such innovations (van Tartwijk, Driessen, van der Vleuten \& Stokking, 2007).

University policies add to the complexity of the issue. For instance, the prevailing philosophy underpinning policies at The Hong Kong Polytechnic University (PolyU) is to implement initiatives to 'maximise the benefits of their [students'] learning and enhance their competitiveness' (PolyU, 2008, p.6). The consequent pressure to produce 'preferred graduates' means that success in competition takes precedence; individuality becomes an optional extra. While e-portfolios purport to offer a personalised tool for students to interrogate their learning experiences, and to explore the emotional aspect of learning, this occurs within a traditional, lecture-based higher educational framework which often accords low priority to students' individuality or emotional responses to teaching and learning. In this context, paradoxically, e- 
portfolios originally intended as an empowering device run the risk of heightening students' sense of disempowerment, as they struggle to reconcile their own vulnerability with the power hierarchies within institutions and wider society (Burke \& Dunn, 2006).

Some students may find appeal in the notion of e-portfolios being useful for graduation or post-university employment. However, the audience implied by such eportfolios as a bureaucratic exercise or job artifact renders it unlikely that students will engage in any profound, frank examination of their own learning. In allowing students to compile e-portfolios in which they develop a propensity to gloss over weaknesses and problems of their learning, we may be signaling to them that flaws and failures ought to be hidden. Another issue is, for the majority of teachers, a top down approach - where e-portfolio use is seen as externally mandated - may spawn a sense of coercion to participate, where the 'e' in e-portfolios may connote extra time and effort, extraneous duty, and erosion of teacher control or even authority.

\section{Conclusion and suggestions}

Since the reported findings are of individual experiences, and are indicative of the contextual background at pre- and post-event times, any generalised conclusions should be subject to further scrutiny. Nonetheless, reporting the experiences of participants using e-portfolios for developing independent learning has helped to address the following two research questions: 1) What are the views of university students and teachers on e-portfolios for developing independent learning? 2) What challenges exist in developing independent learning through e-portfolios at university?

Five themes emerged from the findings suggest that e-portfolio practice facilitates a three-phase cycle of independent learning through:

- Planning: self-identified goals and choice of artifacts using technological skills appropriate to the task

- Monitoring: review of individual progress towards one's goals from a dual perspective of learning being a product and a process, aided by teacher feedback

- Reflecting: modification of goals and/or deployment of repair strategies for further improvement

While lending credence to the value of e-portfolios for cultivating independent learning, the reported findings also throw in relief the challenges in three key areas: the 'clone' phenomenon of student performance, teacher identity, and institutional policy. Where the students' desire to meet evaluation criteria prevails, the potential of e-portfolios for individualised developmental performance is eroded. Where teachers struggle to forge their identity in the shift towards a learner-centred paradigm without appropriate and adequate scaffolding, e-portfolios may be seen as another externally mandated exercise in which teachers are coerced to participate. Where institutional policy takes developing graduates' competitiveness as its focus, e-portfolios bear the risk of perpetuating a culture of 'dressing up' achievements at the expense of candid interrogation of weakness for progress.

There are other compelling questions: What are the long-term effects of e-portfolio practice on independent learning, suggesting the need for more longitudinal studies? 
Does e-portfolio practice vary with disciplinary background and access to computer facilities, implying issues of digital disparity? To what extent would e-portfolios as an assessment tool impact on examination-oriented Chinese learners, pointing to ethnicity-related factors? The above discussion serves to illustrate not only the considerable divergence in educational priorities, but also that e-portfolio practice involves a complicated interplay or conflict of various factors that may thwart the good intentions of its introduction.

A crucial issue in all stages of our education consists in improving the quality of learner outcomes. Although e-portfolio-mediated pedagogy has been advanced as effective for aligning learning contexts with learner preferences and informal learning accomplishments, and ultimately providing students a forum for reflecting on their accomplishments, relevant research reports a mix of merit and conflict. Seeking a way forward is to conceptualise e-portfolio practice as an integral part of pedagogical or curricular reform, embedding it in the right way and giving it the right kind of support (Little, 2009). This can be understood as four principles of e-portfolio design:

- to align learning goals with the content and structure of curricula

- to reflect the context of implementation so that teachers and learners can access a range of opportunities to explore different approaches when operating at the interface of knowledge construction, social interaction and independent learning

- to provide multi-dimensional scaffolding for teacher and learner beyond that of technology

- to sponsor teacher and learner investment by providing built in facilities that take account of their unique socio-historical development of a sense of self and identity

To develop independent learning within an e-portfolio environment requires commitment, purpose, strategies, and due recognition of the human dimension of learning. A teacher in this research observed:

\begin{abstract}
e-portfolios are useful in getting students involved in another aspect of independent learning using the media that we have now in the technology. I thought that was probably a very valuable experience and I thought that was quite interesting to try to judge not just language abilities but what kind of person he or she was, a person who is writing and sharing interesting things with me.
\end{abstract}

In conclusion, e-portfolios can serve conceptually as an independent learning tool, but there are also implementation challenges facing students, teachers and institutions. These challenges should not be construed as a straitjacket. Just as many e-initiatives are often marked by tensions and frustrations when striving for a long-term impact, so the evolving nature of e-portfolios signifies a journey that has just begun, rather than completed.

\title{
Acknowledgments
}

Our gratitude goes to the University Grants Committee (Hong Kong) and the Educational Development Centre of The Hong Kong Polytechnic University for funding support. We also owe special thanks to Peggy Lui for her incredible technical support. 


\section{References}

Abrami, P. C. \& Barrett, H. (2005). Directions for research and development on electronic portfolios. Canadian Journal of Learning and Technology, 31(3). http:/ / www.cjlt.ca/index.php/cjlt/ article/viewArticle/92/86

Abrami, P. C., Wade, C. A., Pillay, V., Aslan, O., Bures, E. M. \& Bentley, C. (2008). Encouraging self-regulated learning through electronic portfolios. Canadian Journal of Learning and Technology, 34(3). http:/ / www.cjlt.ca/index.php/cjlt/article/viewArticle/507 / 238

Andrade, M. S. \& Bunker, E. L. (2009). A model for self-regulated distance language learning. Distance Education, 30(1), 47-61.

Arkoudis, S. \& Love, K. (2008). Imagined communities in senior school mathematics: Beyond issues of English language ability. Journal of Asian Pacific Communication, 18(1), 71-90.

Barnett, L. (1993).Teacher off: Computer technology, guidance and self-access. System, 21(3), 295304.

Benson, P. (2005). (Auto) biography and learner diversity. In P. Benson \& D. Nunan (Eds.), Learners' stories: Difference and diversity in language learning (pp.4-21). Cambridge: Cambridge University Press.

Benson, P. (2006). Autonomy in language teaching and learning. Language Teaching, 40, 21-40.

Burke, P. J. \& Dunn, S. (2006). Communicating science: Exploring reflexive pedagogical approaches, Teaching in Higher Education, 11(2), 219-213.

Butler, D. L. \& Winne, P. H. (1995). Feedback and self-regulated learning: A theoretical synthesis. Review of Educational Research, 65(3), 245-281.

Cambridge, D. (2008). Audience, integrity, and the living document: eFolio Minnesota and lifelong and lifewide learning with ePortfolios. Computers $\mathcal{E}$ Education, 51(3), 1227-1246.

Chamot, A. U. (2005). Language learning strategy instruction: Current issues and research. Annual Review of Applied Linguistics, 25, 112-130.

Charmaz, K. (2006). Constructing grounded theory: A practical guide through qualitative analysis. London: Sage Publications.

Cummins, P. W. \& Davesne, C. (2009). Using electronic portfolios for second language assessment. Modern Language Journal, 93(1), 848-867.

Deci, E. L. \& Flaste, R. (1996). Why we do what we do: Understanding self-motivation. New York: Penguin.

Foti, S. \& Ring, G. L. (2008). From ePortfolios to iPortfolios: The find, refine, design, and bind model. Canadian Journal of Learning and Technology, 34(3). http: / / www.cjlt.ca/index.php/cjlt/ article/viewArticle/506/237

Gillham, B. (2000). The research interview. London: Continuum.

Gülbahar, Y. \& Tinmaz, H. (2006). Implementing project-based learning and e-portfolio assessment in an undergraduate course. Journal of Research on Technology in Education, 38(3), 309-327.

Hartnell-Young, E., Harrison, C., Crook, C., Joyes, G., Davies, L., Fisher, T., Pemberton, R. \& Smallwood, A. (2007). The impact of e-portfolios on learning. Coventry: British Educational Communications and Technology Agency (Becta). [verified 13 Dec 2010] http: / / partners.becta.org.uk/index.php?section=rh\&catcode=_re_rp_02\&rid=14007 
Herrington, J., Herrington, A., Mantei, J., Olney, I. \& Ferry, B. (2009). Using mobile technologies to develop new ways of teaching and learning. In J. Herrington, A. Herrington, J. Mantei, I. Olney \& B. Ferry (Eds.), New technologies, new pedagogies: Mobile learning in higher education (pp.1-14). University of Wollongong, Australia. http:/ / ro.uow.edu.au/newtech/

Hong Kong Polytechnic University (2008). Strategic Plan 2008/09-2011/12: Achieving Excellence in an Era of Challenge. Hong Kong: The Hong Kong Polytechnic University.

JISC (2008). Effective practice with e-portfolios: Supporting 21st century learning. http:/ / www.jisc.ac.uk/media/documents/publications/effectivepracticeeportfolios.pdf

Joyes, G., Gray, L. \& Hartnell-Young, E. (2010). Effective practice with e-portfolios: How can the UK experience inform implementation? Australasian Journal of Educational Technology, 26(1), 15-27. http: / / www.ascilite.org.au/ajet/ajet26/joyes.html

Kicken, W., Brand-Gruwel, S., van Merrienboer, J. J. G. \& Slot, W. (2009). The effects of portfoliobased advice on the development of self-directed learning skills in secondary vocational education. Educational Technology Research and Development, 57(4), 439-460.

Kolb, D. A. (1984). Experiential learning: experience as the source of learning and development. Englewood Cliffs, NJ: Prentice-Hall.

Little, D. (1995). Learning as dialogue: The dependence of learner autonomy on teacher autonomy. System, 23(2), 175-182.

Little, D. (2009). Language learner autonomy and the European Language Portfolio: Two L2 English examples. Language Teaching, 42(2), 222-233.

Meeus, W., van Petegem, P. \& Engels, N. (2009). Validity and reliability of portfolio assessment in pre-service teacher education. Assessment E Evaluation in Higher Education, 34(4), 401-413.

Meeus, W., van Petegem, P. \& Meijer, J. (2008). Portfolio as a means of promoting autonomous learning in teacher education: A quasi-experimental study. Educational Research, 50(4), 361386.

Milman, N. B. \& Kilbane, C.R. (2005). Digital teaching portfolios: Catalysts for fostering authentic professional development. Canadian Journal of Learning and Technology, 31(3). http: / / www.cjlt.ca/index.php/cjlt/article/view/95/ 89

Mishler, E. G. (1986). Research interviewing: Context and narrative. Cambridge, MA: Harvard University Press.

Moskaliuk, J., Kimmerle, J. \& Cress, U. (2009). Wiki-supported learning and knowledge building: Effects of Incongruity between knowledge and information. Journal of Computer Assisted Learning, 25(6), 549-561.

Paris, S. G. \& Paris, A. H. (2001). Classroom applications of research on self-regulated learning. Educational Psychologist, 36(2), 89-101.

Piaget, J. (1971). Genetic epistemology. New York: W.W. Norton.

Pintrich, P.R. (2000). The role of goal orientation in self-regulated learning. In M. Boekaerts, P. Pintrich \& M. Zeidner (Eds.), Handbook of self-regulation (pp. 451-502). San Diego, CA: Academic.

Pintrich, P. R., \& Schunk, D. (2002). Motivation in education: Theory, research, and applications (2nd ed.). Upper Saddle River, New Jersey: Prentice-Hall.

Richardson, W. (2009). Blogs, wikis, podcasts, and other powerful web tools for classrooms (2nd ed.). Thousand Oaks, CA: Corwin Press. 
Scott, T. (2005). Creating the subject of portfolios: Reflecting writing and the conveyance of institutional prerogatives. Written Communication, 22(3), 1-35.

Sheldon, K. M. \& Elliot, A. J. (1998). Not all personal goals are personal: Comparing autonomous and controlled reasons for goals and predictors of effort and attainment. Personality and Social Psychology Bulletin, 24(5), 546-557.

Silverman, D. (2001). Interpreting qualitative data: Methods for analyzing talk, text and interaction (2nd ed.). London: Sage Publications.

Stefani, L., Manson, R. \& Pegler, C. (2007). The educational potential of eportfolios: Supporting personal development and reflective learning. New York: Routledge.

Stoicovy, C. E. \& Sanchez, J. (2007). Crossing the digital divide: Online portfolios in a diverse student environment. In Y. Inoue (Ed.), Technology and diversity in higher education: New challenges (pp.65-80). Hershey, P.A.: Information Science Publishing.

Strauss, A. \& Corbin, J. (1990). Basics of qualitative research: Grounded theory procedures and techniques. Newbury Park, CA: Sage Publications.

Van Tartwijk, I., Driessen, E., van der Vleuten, C. \& Stokking, K. (2007). Factors influencing the successful introduction of portfolios. Quality in Higher Education, 13(1), 69-79.

Willis, H., Gravestock, P. \& Jenkins, M. (2006). Throwing a pebble into the pond: E-portfolios and student engagement. In who's learning? Whose technology? Proceedings ascilite Sydney 2006. http: / / www.ascilite.org.au/conferences / sydney06/proceeding/pdf_papers/p68.pdf

Willis, L. \& Wilkie, L. (2009). Digital career portfolios: Expanding institutional opportunities. Journal of Employment Counseling, 46(2), 73.

Winne, P. H. (2001). Self-regulated learning viewed from models of information processing. In B. Zimmerman \& D. Schunk (Eds.), Self-regulated learning and academic achievement: Theoretical perspectives (pp. 153-189). Mahwah, NJ: Lawrence Erlbaum Associates.

Woodward, H. \& Nanlohy, P. (2004). Digital portfolios: Fact or fashion? Assessment \& Evaluation in Higher Education, 29(2), 227-238.

Yang, S.-H. (2009). Using blogs to enhance critical reflection and community of practice. Educational Technology E Society, 12(2), 11-21. http: / / www.ifets.info/journals/12_2/2.pdf

Zimmerman, B.J. (2000). Attaining self-regulation: A social cognitive perspective. In M. Boekarts, P. Pintrich \& M. Zeidner (Eds.), Self-regulation: Theory, research, and applications (pp. 13-39). Orlando, FL: Academic.

Juliana Chau, The English Language Centre, The Hong Kong Polytechnic University, Hung Hom, Hong Kong SAR, China.

Corresponding author email: ecjchau@polyu.edu.hk

Web: http: / / elc.polyu.edu.hk/staff/JulianaChau.htm

Gary Cheng, Department of Mathematics and Information Technology, The Hong Kong Institute of Education, 10 Lo Ping Road, Tai Po, NT, Hong Kong SAR, China. Email: chengks@ied.edu.hk

Web: https: / / oraas0.ied.edu.hk/rich/web/people_details.jsp?pid=87136 
Appendix 1: Information to students e-Portfolio Competition February - April 2009

\section{Steps}
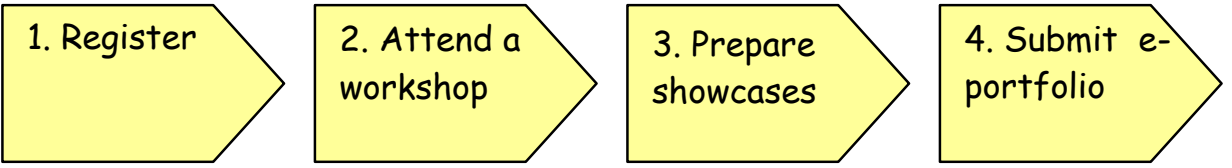

\section{Important dates and instruction}

- $\quad$ Register online by 21 January 2009

(http://eportfolio.elc.polyu.edu.hk/register2009.htm)

- $\quad$ Attend a workshop on 22 January 2009 (A302, 5:30-6:30 pm)

- Create three showcases in your e-portfolio (http://eportfolio.elc.polyu.edu.hk)
- February Showcase (1 - 28 February 2009)
- March Showcase (1 - 31 March 2009)
- April Showcase (1 - 25 April 2009)

Select and present at least FOUR multi-media and text files and provide a reflective entry of about 200 words for each showcase.

\section{Evaluation criteria}

The Selection Panel will evaluate

a. your ability to

- identify the purpose of the showcase

- present evidence of independent language learning in digital form

- explain and make connections between the choice of files in relation to the identified purpose, as well as issues that you think are important to learning English

for more details, see: http://eportfolio.elc.polyu.edu.hk/details.htm

b. according to three levels of performance: 'excellent', 'good' and 'inadequate'

c. using four criteria: 'English language', 'quality of work', 'quantity and variety of work', 'reflection':

i. English language

- Effective use of language

- Reasonable use of language

- Weak language

ii. Quality of work

- High quality of work

- Reasonable quality of work

- Work of poor quality

iii. Quantity and variety of work

- Work includes a wide variety of text \& media files (e.g. audio, video, document, graphics and others)

- $\quad$ Work includes more than one type of file (e.g. text and media)

- Work includes only one type of file / or not much work evident

iv. Reflection

- Work demonstrates clear ability to evaluate learning and progress

- Work demonstrates some ability to evaluate learning and progress

- Work demonstrates little or no ability to evaluate learning and progress

\section{Prizes}

Platinum Award $=\$ 1,000$ Gift voucher

Gold Award $=\$ 700$ Gift voucher 
Silver Award $=\$ 500$ Gift voucher

Bronze Award = \$200 Gift voucher (10 prizes)

Certificate of Merit and Souvenir for participants having fulfilled the requirements of the competition

\section{Selection Panel}

Two English teachers at The Hong Kong Polytechnic University will form the selection panel.

\section{Appendix 2}

\section{A. Face to face semi-structured interview questions for participating teachers}

1. Did you view students'e-portfolio showcases?

2. Did you give feedback on students'e-portfolio showcases?

3. Could you describe your experience in using the e-portfolio - the good and the bad?

4. Do you feel that students achieved their goal(s)?

5. About the e-portfolio for language learning, could you - name the functions you find most / least useful? - name any aspects of the e-portfolio you find most/ least useful

6. What are (were) the main challenges / benefits of using the e-portfolio as an independent language learning tool?

7. How long have you been a teacher for independent language learning - here or elsewhere?

8. Have you had any experience of helping students with independent language learning?

9. Do you have any suggestions / comments for the e-portfolio?

To sum up...

Using the e-portfolio is like...

\section{B. Face to face semi-structured interview questions for participating students}

1. What motivated you to sign up for the e-portfolio competition?

2. Could you describe your experience in using the e-portfolio - the good and the bad?

3. Do you feel that you achieved your goal(s)?

4. About the e-portfolio for language learning, could you

5. Name the functions you find most / least useful?

6. Name any aspects of the e-portfolio you find most/ least useful?

7. What are (were) the main challenges / benefits of using the e-portfolio as an independent language learning tool?

8. How you had any previous experience in using an e-portfolio? Where? When? How? How long?

9. Do you have any suggestions / comments for the e-portfolio?

To sum up...

Using the e-portfolio is like... 


\section{Appendix 3}

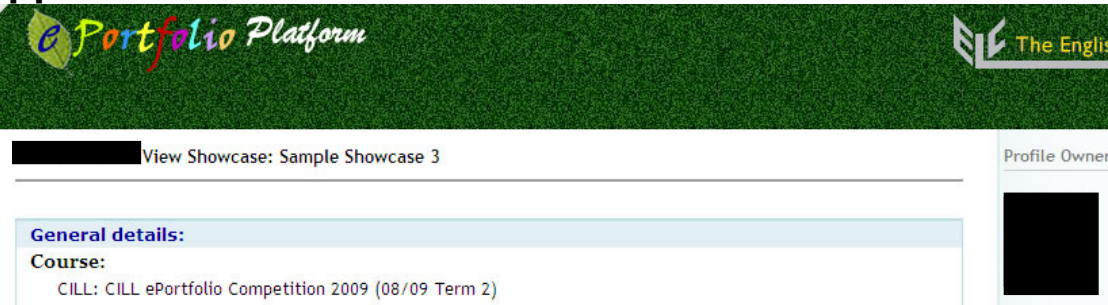

Purpose:

The purpose of this showcase is to:

- I would like to use the April Showcase to develop a portfolio that demonstrated my achievement, progress and improvement in English reading, speaking and listening skills in my daily lives.

Audience:

Class Teacher

Content ( 5 files):

File \#1 of 5

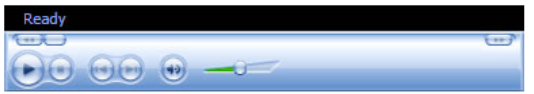

\section{MP3 Title: $\Lambda$ Song

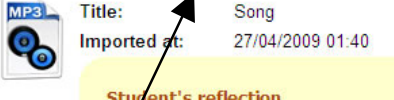 \\ Stufent's reflection romantic. \\ “I don't want to close my eyes, I don't want to fall asleep, \\ Cause I miss you baby, And I don't want to miss a thing,}

My thoughts: "I Don't Want to Miss a Thing" is one of my favorite songs. It's one of

the soundtracks in the song album of the movie called "Armageddon", which's a

touching sci-fi action film. It's a hit single by the American rock band Aerosmith.

Whenever I listen to this song, the scenes in the film will immediately pop up in my mind. Indeed, I love the lyrics of this song very much. The lyrics are so touching and

Artifacts
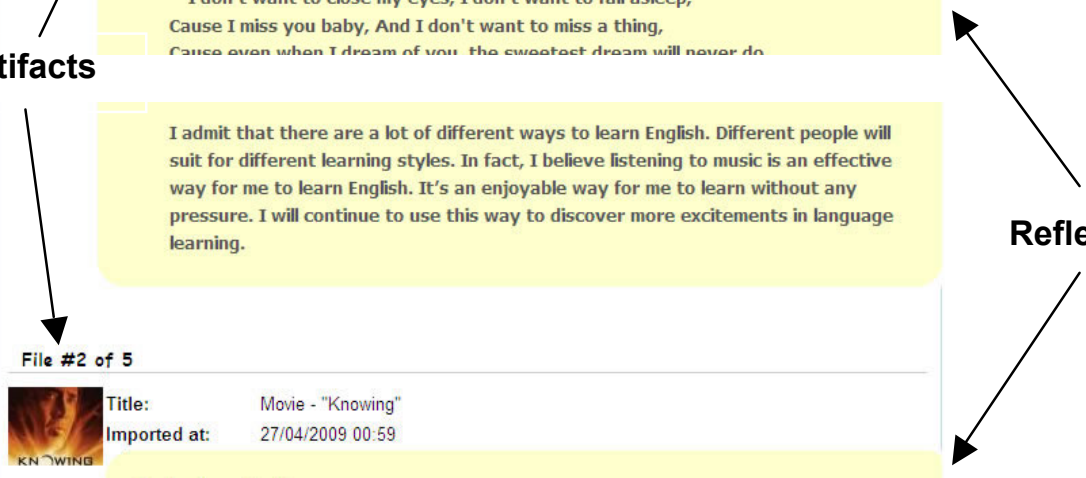

Reflective entries

Student's reflection

1. My thoughts: Last week, I watched the movie of Academy Award-winning actor, Nicholas Cage. The film's called "Knowing" and it revolved around a series of apparently random numbers jotted down by a mysterious girl and put in a time capsule. $\mathbf{5 0}$ years later, the predictive power of those numbers for major disasters was discovered by an astrophysics professor. I liked this latest sci-fi movie. I was really astonished at those disastrous scenes liked the plane crash and subway sequence in the film.

I discover that I can practice my English listening skills not only at school, but also during my leisure time when I watch movies. Even though I really find it hard to catch up with the dialogues sometimes, I think it's a challenging and exciting learning process for me to improve my English. For instance, I can learn the ways of how different people express their feelings. This will in turn benefit my spoken skills as well. 


\section{Appendix 3 (cont.)}

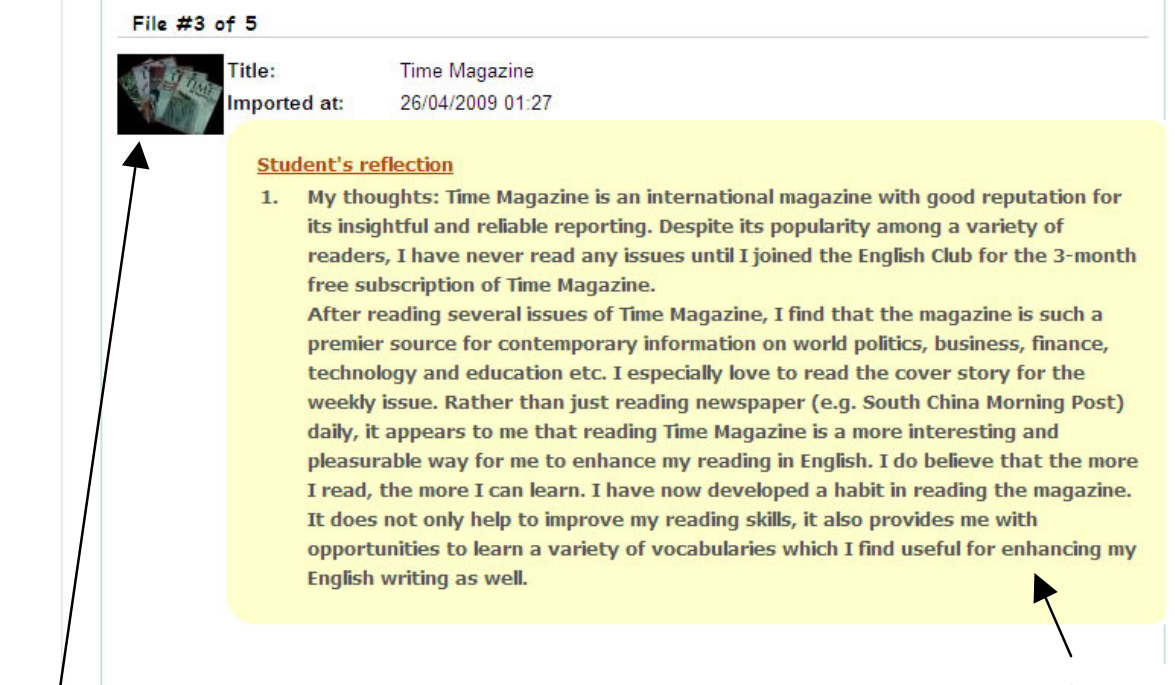

File \#4 of 5

Reflective entries

Artifacts

Certificate

Imported at: 28/04/2009 00:07

4 Student's reflection

1. The file shows that $I$ have some further practice and made progress in:

$$
\text { - speaking }
$$

2. My thoughts: This Certificate of Appreciation was obtained during my exchange study. It served as a recognition of my oral ability in presentation.
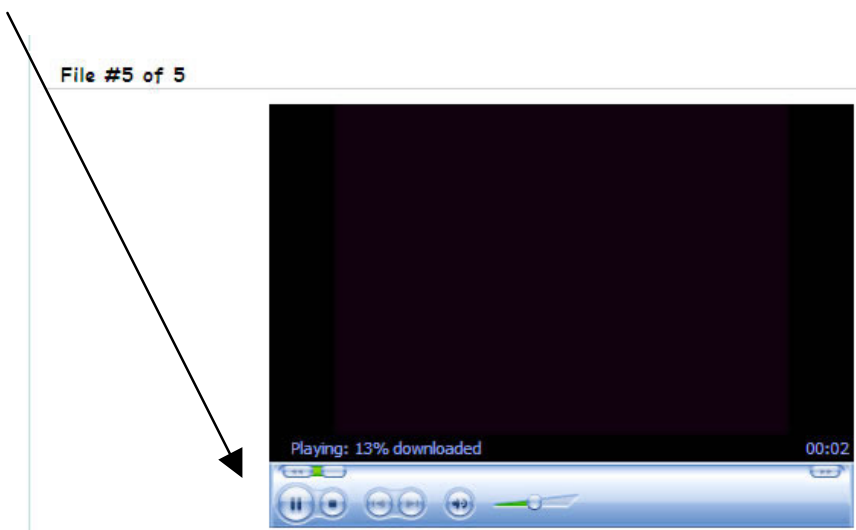

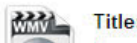

Exchange Program

Imported at:

$25 / 04 / 200923.56$

Student's reflection

1. The file shows that $I$ have fulfilled the purpose of my ePortfolio.

This video presented a sharing of my exchange study in Australia. I really benefited a lot from participating in the exchange program. During my five months exchange study in Australia, I had much improvement and progress in my English language. As I had to use English to communicate with other people all the times, I had plenty of chances to practise both my listening and spoken skills. I am now more comfortable to communicate with others in English as I get used to speak more. 